\title{
A Influência da Raça e do Gênero nas Oportunidades de Obtenção de Renda - Uma Análise da Discriminação em Mercados de Trabalho Distintos: Bahia e São Paulo
}

\author{
Maria Cristina Cacciamali \\ Guilherme Issamu Hirata
}

\author{
Professora Titular da FEA-USP \\ Mestrando em Economia pelo CEDEPLAR/UFMG \\ e bolsista do CNPq
}

\begin{abstract}
RESUMO
O objetivo deste trabalho é verificar a hipótese de discriminação no mercado de trabalho para homens e mulheres, segundo a sua auto-identificação racial - brancos ou pardos e negros - em dois estados brasileiros de predominância étnica distinta: Bahia e São Paulo. Os testes estatísticos foram realizados empregando um modelo probit. Os resultados indicam que a discriminação racial e por gênero estão presentes no mercado de trabalho brasileiro, de acordo com as categorias analisadas - dirigentes e gerentes, empregados com registro e empregados sem registro. Constata-se também que não há indícios de presença de discriminação racial entre os ocupados mais pobres - que pertencem ao primeiro quintil da distribuição de renda familiar per capita - embora neste grupo se verifique a discriminação contra a mulher.
\end{abstract}

\section{PALAVRAS-CHAVE}

discriminação, raça, gênero, discriminação no mercado de trabalho, probit

ABSTRACT

This paper attempts to verify the hypothesis of discrimination in the Brazilian labor market for men and women, according to their racial auto-identification - white or black - in the states of Bahia and São Paulo. A probit model has been applied for the accomplishment of the tests. The results show that the discrimination is alive in the Brazilian labor market against black people and women, especially black women. It was not found any evidence of racial discrimination among the poorest population, but among this group the discrimination against women persists.

KEY WORDS discrimination, race, gender, discrimination in the Brazilian labor market, probit

JEL Classification

J7I 


\section{INTRODUÇÃO}

A Declaração sobre os Princípios e Direitos Fundamentais foi aprovada em junho de 1998, na Conferência Internacional do Trabalho promovida pela Organização Internacional do Trabalho (OIT). ${ }^{1}$ Dentre os quatro princípios que estruturam os Direitos Fundamentais, a eliminação da discriminação com relação ao emprego e ocupação é um reforço para a atuação política dos atores sociais e dos governos com vistas a definir políticas públicas para combater quaisquer tipos de discriminação, sejam estas motivadas por preconceitos de raça, étnico, orientação religiosa, orientação sexual, deficiência física e/ou idade, entre os principais. No Brasil, o debate sobre esse tema centra-se principalmente sobre a discriminação no mercado de trabalho por gênero e raça, embora outras formas de discriminação tenham começado a ganhar relevo, tanto como objeto de estudo quanto pelas reivindicaçôes dos grupos interessados, como, por exemplo, os deficientes físicos e os portadores de HIV.

O objetivo deste trabalho é gerar evidências empíricas adicionais que contribuam para detalhar a análise da discriminação no mercado de trabalho brasileiro e para formular programas e ações de políticas públicas que enfrentem a desigualdade de renda produzida no mercado de trabalho e derivada da discriminação e do preconceito. Assim, o estudo se propõe a verificar a hipótese de discriminação no mercado de trabalho para homens e mulheres, segundo a sua auto-identificação racial - brancos, e pardos e negros - em dois estados brasileiros de predominância étnica distinta: Bahia e São Paulo.

A análise foi desenvolvida seguindo dois eixos. O primeiro examina essa hipótese segundo a situação no emprego dos indivíduos, e para tanto foram selecionadas três categorias que estruturam o mercado de trabalho: Dirigentes e gerentes de empresas; Empregados registrados; e Empregados sem registro. As duas primeiras categorias aproximam o mercado de trabalho formal, que é composto pelos empregos de melhor qualidade, dispondo de contratos de trabalho de acordo com a legislação laboral, incluídos no sistema público de seguridade social, e abarcados pelas negociações coletivas. O grupo dos Dirigentes e gerentes, entretanto, foi destacado dos demais, não apenas pelo seu tipo de inserção hierárquica, pois as atividades de formulação, participação e supervisão dos processos de produção e de trabalho, por si só, são diferenciadoras de remuneração e de condições de trabalho, como também porque essa inserção permite

1 São quatro princípios que regem os direitos fundamentais, a saber: i) livre associação e reconhecimento do direito de negociação coletiva; ii) eliminação de todas as formas de trabalho forçado; iii) efetiva abolição de trabalho infantil; iv) a eliminação da discriminação com relação ao emprego e ocupação. Esses princípios constituem uma base mínima universal de direitos, independentemente de o País ter ratificado as seguintes convenções da OIT: Liberdade de associação e proteção ao direito de organização, 1948, no 87; Direito de organização e de negociação coletiva, 1949, no 98; Trabalho forçado, 1930, no 29; Abolição do trabalho forçado, 1957, no 105; Igualdade de remuneração, 1951, nº 100; Discriminação (emprego e ocupação), 1958, n 111; Idade mínima (para o trabalho), 1973, no 138; Piores formas de trabalho infantil, 1999, $n^{\circ}$ 182. 
estabelecer mecanismos de maior apropriação na renda perante os demais grupos, por meio, por exemplo, de participação de lucros, prêmios, verbas de representação etc. A última categoria - Empregados sem registro reflete situações de emprego de pior qualidade, pelo fato de se constituírem em empregos à margem da legislação trabalhista e da seguridade social pública, pelos menores salários pagos e/ou maior instabilidade dos empregos. Em cada uma das categorias selecionadas analisa-se a situação de homens e mulheres de mesmo nível de escolaridade de acordo com a sua auto-identificação racial. Especificamente, entre os empregados que mantêm relações de emprego formais, além de analisar outros recortes, verifica-se a situação dos jovens recém-formados no ensino médio. Sabe-se que a taxa de desemprego para os jovens é elevada. Porém, alcançado o tão sonhado primeiro emprego com carteira assinada, quais seriam as probabilidades de rendimentos para esses jovens, todos da mesma idade e mesma instrução?

O segundo eixo investiga a discriminação entre os trabalhadores mais pobres, ou seja, aqueles que pertencem ao primeiro quintil da distribuição de renda familiar per capita.

A opção por uma análise comparativa segundo o recorte de inserção no mercado de trabalho, além disso, foi motivada para intentar o exame entre parcelas da população que se situam em empregos de qualidade menos desigual intragrupos, permitindo aprofundar as evidências empíricas sobre a temática. Por outro lado, o estudo da discriminação no mercado de trabalho dos trabalhadores que compóem o primeiro quintil da distribuição de renda familiar per capita tem como finalidade verificar o grau de discriminação entre trabalhadores que, em virtude de suas menores condições de vida material, se defrontam com menos oportunidades perante os demais. Por fim, efetua-se o estudo a partir dos microdados da Pesquisa Nacional por Amostra de Domicílios (PNAD) de 2002, para dois estados da Federação, marcadamente distintos, não apenas com relação ao nível de desenvolvimento econômico, configuração e complexidade do mercado de trabalho, como também nos aspectos sociais, culturais e de predominância étnica - no Estado de São Paulo, pardos e negros constituem $28 \%$ da população, enquanto na Bahia, essa proporção é de 77,9\%. (PNAD, 2002).

Este artigo encontra-se subdividido em quatro seções, além desta introdução e das considerações finais. Na primeira seção expõe-se o embasamento teórico adotado para implementar este estudo, fatos estilizados e evidências empíricas selecionadas da literatura brasileira sobre o tema. A segunda seção aponta os primeiros indícios de discriminação no mercado de trabalho brasileiro. Na terceira apresenta-se a metodologia utilizada e a quarta seção completa o quadro por meio da análise dos resultados encontrados. 


\section{DESIGUALDADE DE RENDA E SUA REPRODUÇÃO NO MERCADO DE TRABALHO}

No campo da discriminação no mercado de trabalho segundo gênero e raça, estudo recente realizado pelo DIEESE (2003) mostra que os negros e as mulheres brancas percebem, nos mercados de trabalho metropolitanos, rendimentos-hora médios mensais substancialmente menores que aqueles auferidos pelos homens brancos. Na Região Metropolitana de São Paulo, na média, com relação aos homens brancos, os homens negros ganham o equivalente a $53,7 \%$ de seu rendimento, as mulheres negras, $42,3 \%$, e as mulheres brancas, $76,6 \%$. Estes porcentuais, por outro lado, são similares aos verificados em outras regióes metropolitanas: em Salvador, por exemplo, eles correspondem a $47,5 \%, 35,7 \%$ e $78,6 \%$, respectivamente. Esses resultados, na realidade, corroboram dois aspectos. O primeiro é o senso comum, confirmado por estudos especializados, que no Brasil a herança escravocrata, de um lado, e a herança patriarcal, de outro, ainda implicam elevado grau de desigualdade de rendimentos no mercado de trabalho. Negros e mulheres enfrentam um ambiente de oportunidades desiguais, especialmente no que diz respeito ao acesso à educação para os negros. O segundo é que as condiçôes anteriores criaram e mantêm um tecido social impregnado de preconceitos que levam à discriminação social e no mercado de trabalho das mulheres, dos pardos e negros, resultando em piores condições de vida material e de mobilidade vertical para essas pessoas e para os grupos sociais nos quais predominam.

As desigualdades sociais e de renda entre brancos e negros podem ser interpretadas de duas maneiras, conforme as sínteses realizadas por Lovell (1992) e Wood e Carvalho (1994). A primeira nos remete à herança escravocrata que ainda permeia as relaçóes sociais no Brasil, redundando em um tratamento inferior para os negros e pardos e consolidando a sua participação nos estratos inferiores da sociedade. A segunda interpretação considera que a discriminação na nossa sociedade se baseia em um preconceito negativo com relação aos mais pobres ao invés de raça. Considerando que a maioria dos pobres é parda e negra, somos levados a confundir a discriminação contra os pobres com discriminação racial. Assim, à medida que negros e pardos ascendam para estratos de renda superiores deixarão de ser discriminados.

A discriminação das mulheres no mercado de trabalho, por outro lado, se sobrepóe àquela de raça e incide, de forma altamente negativa, especialmente sobre a mulher negra. Ela se revela por meio de mecanismos de segregação social e ocupacional instaurados pela tradição patriarcal na nossa sociedade, criando menores oportunidades de mobilidade vertical e estabelecendo salários inferiores para as mulheres, especialmente nos postos de trabalho que predominam. As maiores responsabilidades da mulher no que tange à família e o seu papel na reprodução biológica podem acarretar seu menor envolvimento e descontinuidade no exercício do trabalho. Dessa maneira, esse papel 
social das mulheres contribui para a manutenção de práticas que as discriminam no mercado de trabalho, seja por meio de remuneraçóes menores e/ou de menores investimentos das empresas em treinamento e capacitação para os seus empregados do sexo feminino, restringindo-lhes sua ascensão profissional.

A existência de valores arraigados, numa dada sociedade, que levem à discriminação por raça e/ou gênero, significa que essas características exercem influência no mercado de trabalho, tanto na admissão em um determinado tipo ou relação de emprego quanto na definição de sua remuneração. Ou seja, pessoas que apresentam atributos iguais, exceto quanto à raça e/ou gênero, são valorizadas de forma distinta pelos empregadores ou pelos usuários de serviços, apenas em virtude desses últimos atributos, caracterizando a existência de preconceito que leva a uma discriminação direta. Isso seria o motivo pelo qual o mercado remunera mais adequadamente o homem branco em detrimento dos homens negros e pardos e das mulheres.

Por outro lado, se a discriminação segundo raça e gênero proceder de uma situação de desvantagem de atributos das mulheres, negros e pardos ante os homens brancos no que se refere à escolaridade, experiência, qualificação, capital social e outras características relevantes que influenciam a admissão de uma pessoa em um posto de trabalho, devemos esperar que, no momento em que essas condições se igualem, as distinções de remuneração e/ou de oportunidades entre esses grupos serão eliminadas. Neste caso, a sociedade não encerra um viés discriminador contra mulheres, negros e pardos, e o mercado de trabalho acaba, na realidade, selecionando para os melhores postos de trabalho, de remunerações mais elevadas, aqueles mais bem qualificados. O fato de isso favorecer os brancos, e especialmente o homem branco, deriva das diferentes dotaçôes e condiçôes iniciais dos participantes do mercado de trabalho, que favorecem os brancos, e em especial o homem branco.

Estudos empíricos realizados na década de 1990 apontam resultados que ratificam essas duas interpretaçóes. Os negros e pardos se encontram sobre-representados entre os mais pobres. Henriques (2001), utilizando dados da PNAD para 1999, evidencia que negros e pardos representam $45 \%$ do total da população, $64 \%$ da população abaixo da linha da pobreza, $69 \%$ abaixo da linha de indigência ${ }^{2}$ e $70 \%$ dos $10 \%$ mais pobres do País. Adicionalmente, estudo realizado por Ramos e Vieira (2000), sobre os determinantes da desigualdade de renda no Brasil ao longo da década de 1990 (1992, 1995 e 1997), utilizando um método de decomposição estática, aponta que a discriminação segundo raça é responsável por cerca de $8 \%$ da desigualdade de renda, sobressaindo a educação e a posição na ocupação como as principais causas da desigualdade, com por-

2 A linha de indigentes refere-se aos custos de uma cesta alimentar, regionalmente definida, que atenda às necessidades de consumo calórico mínimo de um indivíduo, enquanto a linha da pobreza inclui, além dos gastos com alimentação, um mínimo de gastos individuais com vestuário, habitação e transportes. 
centagem conjunta entre $40 \%$ e $45 \%$. Apesar de $8 \%$ ser um indício da influência relativamente diminuta perante a magnitude dos diferenciais, observa-se que a participação da discriminação apresenta tendência crescente ao longo da década, aumentando $26 \%$ entre os anos de 1992 e 1997. Soares, por outro lado, analisando a evolução da desigualdade salarial entre 1987 e 1997, por meio do método de decomposição de Oaxaca, alcança resultados mais significativos. (Soares, 2000). As mulheres brancas apresentam o menor diferencial com relação ao chamado grupo-padrão: os homens brancos. Porém, os retornos salariais gerados por meio da obtenção de educação e experiência são sobrepujados pela discriminação devido ao preconceito de gênero, pois elas chegam a perceber uma diferença salarial em torno de $35 \%$. Os homens negros apresentam maior defasagem salarial em termos de qualificação, ou seja, a discriminação ocorre no momento de sua formação educacional, e o mercado de trabalho, nesse caso, atua muito mais como ratificador da desigualdade do que gerador, ao contrário da situação verificada para as mulheres brancas. Um ponto a frisar é que a diferença salarial do homem negro com relação ao homem branco cresce com o aumento da renda do primeiro, evidenciando que a obtenção de educação e a experiência não são suficientes para dar fim à discriminação contra os negros. A situação das mulheres negras é indubitavelmente a pior, pois experimentam dupla discriminação: por serem mulheres e por serem negras. Recebem cerca de 33\% do salário dos homens brancos em 1987, e atingem 40\% em 1998. Aliás, essa tendência, vagarosa, de diminuição do diferencial de salário segundo gênero, é a única constatação positiva na análise realizada por Soares (2000), não tendo sido constatada para as desagregações segundo a raça.

A teoria econômica dispõe de diferentes interpretações sobre a discriminação no mercado de trabalho, ${ }^{3}$ entre elas selecionamos o modelo de preconceito pessoal proposto e desenvolvido inicialmente por Arrow (1980) por sua clareza, precisão e poder de explicação. Além dessas qualidades, e em virtude delas, esse modelo permite a definição de testes estatísticos relativamente simples para a verificação da hipótese de discriminação salarial. O modelo de Arrow trata da situação na qual empregadores, usuários de serviços e os próprios colegas de emprego têm aversão, em maior ou menor grau, de se relacionar com pessoas de determinadas características, evidenciando o preconceito. $\mathrm{O}$ conceito-chave para explicar a discriminação, segundo o autor, é a desutilidade que um agente econômico se defronta na presença de uma pessoa portadora de uma característica que, devido à existência de um preconceito, ele considera indesejável. Essa situação leva à discriminação da pessoa ou do grupo portador dessa característica, pois o empregador desvaloriza a produtividade do candidato ao emprego que a apresenta. Mesmo que esse trabalhador possua semelhante qualificação e potencial que outro

3 Veja-se, por exemplo, os capítulos referentes ao tema da discriminação no mercado de trabalho dos livros de Borjas (1996) e Ehrenberg e Smith (1997), nos quais os autores resenham as principais teorias econômicas neoclássicas sobre o tema, entre as quais destacamos os modelos de discriminação estatística e não competitivos. 
candidato, o empregador o considerará menos produtivo. Isso porque, segundo Arrow, o empregador possui uma utilidade marginal negativa com relação aos candidatos que não se enquadram no seu perfil adequado preconcebido. De modo que, atuando no sentido de maximizar a sua utilidade, o empregador tomará a sua decisão sobre a admissão de um candidato levando em conta o número de empregados com tais características. Assim, o salário do trabalhador discriminado será igual ao valor de sua produtividade marginal desvalorizada pelo empregador. Quanto maior for a discriminação, maior será a desvalorização e, portanto, menor será o salário. Para aqueles que não são alvos do preconceito, o salário será determinado de acordo com a sua verdadeira produtividade marginal.

Sob a hipótese de que os trabalhadores são substitutos perfeitos e, portanto, possuem a mesma produtividade marginal, o empregador que não pratica a discriminação maximiza lucros, contratando trabalhadores até o salário igualar a produtividade marginal. Porém, quando há discriminação, o equilíbrio no mercado de trabalho, de acordo com Arrow, é possível somente quando o salário dos trabalhadores sobre os quais não pesa o preconceito estiver acima de sua produtividade marginal, e o salário daqueles que são vítimas do preconceito estiver abaixo. Isso ocorre porque o empregador que discrimina, maximiza a sua utilidade e não o lucro. Dessa forma, o empregador que discrimina não se ajusta ao postulado da teoria neoclássica de que o volume de contrataçóes é determinado quando o salário é igual à produtividade marginal; o equilíbrio, neste caso, ocorre em uma situação na qual ele contrata relativamente menos trabalhadores discriminados, e relativamente mais trabalhadores não discriminados. A contratação de trabalhadores discriminados é interrompida antes que a produtividade marginal iguale $o$ salário; e a contratação de trabalhadores não discriminados é realizada até um ponto em que produtividade marginal está além do salário recebido.

O interessante neste modelo é que se o empregador preconceituoso realmente praticar a discriminação, seu lucro não será o máximo possível, pois contratará empregados aquém do que seria o ponto ótimo, ou seja, contratará trabalhadores em um ponto onde a produtividade marginal não é igual ao salário. Se a oferta de trabalhadores passíveis de serem discriminados é pequena, ela será absorvida totalmente por aqueles empregadores que não discriminam, de forma que os empregadores discriminadores podem obter lucro máximo, uma vez que somente contratarão trabalhadores de suas preferências. Entretanto, se a oferta for abundante, os empregadores que discriminam não maximizam lucros, pois terão de contratar trabalhadores de características indesejáveis que não foram absorvidos pelas empresas que não discriminam. Na prática, o coeficiente de discriminação, $d$, que indica a desutilidade ou desvalorização da produtividade marginal do trabalhador, é medido por meio dos diferenciais de salário. Neste artigo, porém, utilizamos probabilidades como medida para aquele coeficiente. 
2. CARACTERIZAÇÃO DAS CATEGORIAS E/OU GRUPOS SELECIONADOS DE ACORDO COM OS DOIS EIXOS DE ANÁLISE: PRIMEIROS INDÍCIOS DE DISCRIMINAÇÃO POR GÊNERO E RAÇA NO MERCADO DE TRABALHO BRASILEIRO

A população brasileira, de acordo com a PNAD de 2002, se distribui na mesma proporção entre pardos, negros e indígenas - 50,6\%, e brancos - 49,4\%. Nos Estados da Bahia e de São Paulo, esses relativos são de 77,9 e de $28 \%$, respectivamente, para o grupo da população que se auto-identifica como parda e negra. A elevada predominância de pardos e negros no Estado da Bahia não impede, entretanto, que se mantenha nos dois estados o mesmo perfil segundo a situação no emprego e a auto-identificação racial. Negros e pardos se encontram sub-representados nas categorias que mostram melhor qualidade de emprego, Empregados com registro e especialmente entre Dirigentes e gerentes, ao contrário dos brancos, que se encontram sobre-representados nessas categorias e sub-representados nas categorias Empregados sem registro e entre os Trabalhadores do primeiro quintil de renda familiar per capita (Tabela 1).

\section{TABELA 1 - COMPOSIÇÃO DA POPULAÇÃO OCUPADA SEGUNDO COR/ RAÇA - BAHIA E SÃO PAULO - 2002}

\begin{tabular}{lccccc}
\hline Grupo & \multicolumn{2}{c}{ Bahia } & & \multicolumn{2}{c}{ São Paulo } \\
\cline { 2 - 3 } \cline { 5 - 6 } & Negros & Brancos & & Negros & Brancos \\
\hline Dirigentes e Gerentes & 55,6 & 44,4 & & 10,8 & 89,2 \\
Empregados com Carteira & 76,5 & 23,5 & & 27,2 & 72,8 \\
Empregados sem Carteira & 79,9 & 20,1 & & 31,0 & 69,0 \\
Primeiro Quintil & 82,2 & 17,8 & & 43,0 & 57,0 \\
População & 77,9 & 22,1 & & 28,0 & 72,0 \\
\hline
\end{tabular}

Fonte: Elaboração Própria. PNAD 2002 - Microdados.

As rendas médias e medianas ratificam as notações anteriores, e geram indícios sobre a presença de dois tipos de discriminação: raça e gênero (Tabela 2). No primeiro tipo, os brancos apresentam indicadores de renda média e mediana superiores aos pardos e negros, e no segundo tipo os homens mostram indicadores superiores aos das mulheres. Esta hierarquia de remunerações é constatada freqüentemente na literatura, apontando ainda que a discriminação por raça é maior do que por gênero. (Soares, 2000; Ramos e Viera, 2000; DIEESE 2003). No entanto, detectamos neste estudo algumas singularidades e exceções. Entre os Dirigentes e gerentes, a mulher branca mostra renda mediana superior ao homem pardo e negro, mas a renda média é inferior. Isto significa que a distribuição dos rendimentos entre as mulheres brancas é menos desigual do que entre os homens pardos e negros, ou seja, entre esses últimos existem ocupados que re- 
cebem remunerações bastante elevadas, implicando média maior, mas não em uma distribuição menos desigual, pois a mediana é menor entre os homens pardos e negros do que entre as mulheres brancas.

Entre os trabalhadores das famílias mais pobres verificam-se níveis de renda média e mediana ligeiramente inferiores para a população branca, tanto masculina como feminina, podendo sugerir que a população branca pobre tem maior dificuldade de acesso a determinadas ocupaçóes, ou se recusa a exercê-las, ou possui relativamente mais condições materiais para optar pelo desemprego ou pela inatividade.

TABELA 2 - RENDA MÉDIA E MEDIANA DE HOMENS E MULHERES, NEGROS E BRANCOS, SEGUNDO GRUPOS ESCOLHIDOS - BAHIA E SÃO PAULO - 2002 - Em RS

\begin{tabular}{|c|c|c|c|c|c|c|c|c|}
\hline \multirow[b]{3}{*}{ Renda Média } & \multicolumn{4}{|c|}{ Bahia } & \multicolumn{4}{|c|}{ São Paulo } \\
\hline & \multicolumn{2}{|c|}{ Negros } & \multicolumn{2}{|c|}{ Brancos } & \multicolumn{2}{|c|}{ Negros } & \multicolumn{2}{|c|}{ Brancos } \\
\hline & Homem & Mulher & Homem & Mulher & Homem & Mulher & Homem & Mulher \\
\hline Dirigentes e Gerentes & 1381,91 & 875,84 & 2156,58 & 1352,10 & 1962,10 & 1019,74 & 2928,69 & 1951,53 \\
\hline Empregado com carteira & 483,37 & 400,37 & 869,78 & 707,05 & 635,52 & 506,74 & 1053,38 & 788,00 \\
\hline Empregado sem carteira & 225,27 & 210,24 & 328,55 & 318,86 & 399,12 & 320,54 & 633,90 & 532,18 \\
\hline Primeiro Quintil & 114,37 & 54,15 & 112,00 & 46,10 & 194,18 & 148,26 & 191,20 & 129,71 \\
\hline \multicolumn{9}{|l|}{ Renda Mediana } \\
\hline Dirigentes e Gerentes & 700,00 & 500,00 & 1425,00 & 775,00 & 1000,00 & 800,00 & 2000,00 & 1500,00 \\
\hline Empregado com carteira & 308,50 & 280,00 & 450,00 & 390,00 & 500,00 & 400,00 & 600,00 & 490,00 \\
\hline Empregado sem carteira & 180,00 & 180,00 & 200,00 & 200,00 & 300,00 & 250,00 & 350,00 & 300,00 \\
\hline Primeiro Quintil & 100,00 & 30,00 & 100,00 & 0,00 & 200,00 & 150,00 & 200,00 & 120,00 \\
\hline
\end{tabular}

Fonte: Elaboração própria. PNAD 2002 - microdados.

A análise segundo os níveis de escolaridade expõe que a ocupação de Dirigentes e gerentes, conforme esperado, detém o maior porcentual de integrantes com o segundo ou terceiro ciclos completos, justificando as maiores remunerações médias e medianas perante as demais categorias, seja pelos cargos ocupados e/ou pelo grau de escolaridade. Na seqüência, em ordem decrescente, de acordo com o critério de porcentagem de integrantes de níveis de escolaridade mais elevados, situam-se as categorias de Empregados com registro e Empregados sem registro e, por fim, os Trabalhadores do primeiro quintil de renda familiar per capita, confirmando o fato de que os indivíduos de maior escolaridade ocupam postos de trabalho de melhor qualidade e segurança. 
Percebe-se que pardos e negros, de modo geral, se encontram em situação de desvantagem com relação aos níveis escolares, concentrando-se nos níveis até o ensino fundamental completo, e mostrando, relativamente aos brancos, menor porcentual de universitários. Esses resultados geram a primeira evidência de que os postos de trabalho de melhor qualidade e segurança são ocupados por indivíduos de escolaridade mais elevada nos dois estados. O diferencial de rendimentos entre os Estados da Bahia e São Paulo, contudo, não encontra respaldo pelos níveis de escolaridade, pois os baianos, em média, possuem maior proporção de ocupados a partir do ensino médio incompleto. Dessa maneira, os diferenciais devem ser remetidos às condiçôes de oferta e demanda dos dois mercados de trabalho e aos níveis mais elevados de produtividade alcançados pelos trabalhadores em São Paulo, devido ao ambiente econômico mais denso e intensivo em tecnologia. 4

As mulheres, na maior parte dos grupos em análise, apresentam maiores níveis de escolaridade ante os homens, contudo, contrariando o esperado, ganham muito menos que os homens, independentemente de sua auto-identificação racial. Dentre os grupos analisados, o maior diferencial de renda refere-se aos Dirigentes e gerentes, indicando uma correlação positiva entre nível de educação e discriminação neste grupo. O homem pardo e negro, a mulher branca e a mulher parda e negra no Estado da Bahia recebem, respectivamente, $64,1 \%, 62,6 \%$ e $40,6 \%$ do salário do homem branco; para São Paulo, os porcentuais são 67\%, 66,6\% e 34,8\%, respectivamente. Isto significa que a maioria das pessoas não consegue traduzir o nível educacional obtido em maiores rendimentos com a mesma eficiência com que o homem branco o faz. A situação da mulher parda e negra, de longe, é a pior. Mesmo apresentando alta escolaridade, estando na mesma ocupação, e dentro do mesmo estado, ela aufere apenas $2 / 5$ e 1/3 do salário do homem branco.

Entre os Empregados com registro a situação é diferente. O homem branco continua com salários mais elevados, mas a diferença é menor com relação às mulheres brancas. O que se nota é a inversão de posições dessas últimas com relação aos homens pardos e negros. O maior salário dos homens brancos pode estar sendo excessivamente influenciado pelos rendimentos daqueles de nível superior, faixa educacional em que eles têm maior proporção relativamente aos demais. As mulheres negras, por outro lado, se defrontam com as piores condições, mesmo possuindo o segundo ciclo de escolaridade.

Nos empregos de menor qualificação, os diferenciais, atendendo às expectativas, diminuem com relação ao homem branco, sendo mais evidente essa queda na Bahia do que em São Paulo. A escolaridade das mulheres brancas entre os Empregados sem registro tem mais influência sobre os seus rendimentos que nos demais grupos analisados,

4 A renda média dos ocupados no Estado da Bahia é R\$ 351,03 e a renda mediana de R\$ 200,00; Em São Paulo, os valores são R \$ 818,88 e R \$ 451,50, respectivamente. 
maior na Bahia do que em São Paulo. Elas recebem o equivalente a 97\% dos homens brancos na Bahia e $84 \%$ em São Paulo. Esse "efeito educação" também pode ser observado no caso dos pardos e negros, embora a diferença salarial se mantenha elevada.

Por fim, os trabalhadores que se encontram no primeiro quintil de renda familiar per capita reforçam a discriminação contra a mulher. As rendas média e mediana são praticamente idênticas para os homens, levando a crer que a discriminação segundo a cor da pele é praticamente inexistente no estrato mais pobre da população. Para as mulheres, em evidente desvantagem segundo este critério de renda média, as pardas e negras apresentam leve vantagem sobre as brancas. A análise por meio da educação permite dizer apenas que a média salarial mais elevada em São Paulo decorre de maior escolaridade. E essa mesma escolaridade volta a não fazer efeito para as mulheres, na medida em que em todos os grupos a proporção em cada nível de escolaridade é muito próxima.

Até o momento percebe-se, pelas informações produzidas, o indício de discriminação no mercado de trabalho, e dependendo do grupo analisado prepondera ora a racial, ora a por gênero. Não podemos ignorar resultados tão enfáticos. No entanto, a discriminação que observamos pode estar enviesada, pois não considera inúmeros fatores. A idade, por exemplo, não foi levada em conta; os agrupamentos de escolaridade podem esconder diferenças de até quatro anos de estudo; e a renda média, todos sabemos, não pode ser considerada uma boa medida estatística, pois o peso de valores extremos é excessivo. No intuito de realizar uma análise mais elaborada e estatisticamente consistente acerca da discriminação no mercado de trabalho, analisaremos, na próxima seção, os diferenciais de salário por meio da estimação de um modelo com variável dependente discreta, mais especificamente, o modelo probit.

\section{MODELO}

Utilizou-se um modelo probit cuja variável dependente indica a situação do ocupado perante uma renda especificada - obtém no máximo aquela renda (inclusive o limite) ou ganha mais. Tal situação deverá ser explicada por um vetor $\left(\mathrm{X}_{\mathrm{i}}\right)$ com as seguintes características: raça, gênero, idade e escolaridade, sendo as duas primeiras variáveis dummies. Temos, portanto:

$$
\mathrm{Y}_{\mathrm{i}}=\alpha+\beta \mathrm{X}_{\mathrm{i}}+\varepsilon_{\mathrm{i}}
$$

$\mathrm{Y}_{\mathrm{i}}=1$, se a renda ${ }^{5}$ do ocupado i é maior que RS Y; e 0 , se menor ou igual

$\mathrm{X}_{1}=1$, se o ocupado se autodeclarar pardo ou negro; e 0 , se branco

5 Renda, em R $\$$ de 2002, no trabalho principal na semana de referência da pesquisa, de 23 a 30 de setembro de 2002. A renda para todos os ocupados foi padronizada para 40 horas semanais. 
$\mathrm{X}_{2}=1$, se o ocupado for do sexo feminino; e 0 , se masculino

$\mathrm{X}_{3}=$ idade

$\mathrm{X}_{4}=$ escolaridade, em anos de estudo

O objetivo é comparar dois indivíduos com as mesmas características, exceto a sua cor/ raça e gênero. A comparação é realizada intra-estados, intracategorias, na mesma faixa etária, e no mesmo nível educacional, buscando minimizar, respectivamente, diferenças decorrentes de efeitos regionais; de oportunidades no mercado e da qualidade da ocupação; da experiência no trabalho devido à idade; e da influência da escolaridade sobre os salários.

A comparação virá por meio da estimação da probabilidade dos ocupados auferirem rendimento acima de RS Y no trabalho principal, sendo Y uma variável de renda com valores múltiplos de RS 100,00. Assim, para cada $\mathrm{Y}$, teremos uma probabilidade $\mathrm{P}$ para cada ocupado, sendo a diferença entre os 'P's' a medida da discriminação. Poderíamos realizar as estimaçôes para intervalos menores de renda, por exemplo, para múltiplos de 50, de 10, de 1 real. Essa opção não alteraria os resultados. Inclusive, sabe-se, que para cada "tipo" de ocupado poderíamos calcular a probabilidade conforme variamos a renda infinitesimalmente, e, no limite, obteríamos uma curva contínua, sendo a distância vertical entre essas linhas a visualização da discriminação, ou sua magnitude em termos de probabilidade. No presente estudo, escolheu-se ficar com os múltiplos de R\$ 100,00.

Partimos das seguintes hipóteses:

- a inclinação de cada curva é negativa, pois conforme a renda escolhida aumenta, a probabilidade de um ocupado apresentar rendimento acima da desta renda diminui;

- a inclinação das curvas para ocupados pardos ou negros deve ser maior que para brancos, mostrando que para dois ocupados com características idênticas a raça influencia negativamente os seus rendimentos;

- a inclinação das curvas referente às mulheres deve ser maior relativamente à dos homens, indicando a discriminação por gênero. 


\section{ESTIMATIVAS E RESULTADOS}

\section{Dirigentes e Gerentes}

Esta categoria comporta pessoas com experiência no mercado de trabalho, e dessa maneira inclui ocupados normalmente acima dos 30 anos de idade e de nível de escolaridade superior à média da população. Os homens brancos, conforme apresentado anteriormente, se constituem no grupo majoritário dessa categoria, embora as mulheres brancas e os homens pardos e negros estejam ampliando a sua participação. Procurando eliminar os efeitos que não a raça e o gênero selecionamos dois ensaios: Ocupados de 30 anos e nível superior completo; e Ocupados de 30 anos e ensino médio completo.

Conforme pode ser observado nos Gráficos 1 e 2, para o Estado de São Paulo, e 3 e 4, para o Estado da Bahia, as probabilidades dos ocupados de ensino médio completo caem mais rapidamente em relação aos ocupados de nível superior, indicando, conforme o esperado, um retorno maior para aqueles que possuem maior escolaridade. As probabilidades dos homens brancos se situam sempre acima das mulheres e dos homens pardos e negros. A mulher negra mostra sempre a pior colocação dentre os demais grupos. $\mathrm{O}$ controle por escolaridade não implica aumento das probabilidades de auferir rendimentos iguais aos demais. A mulher negra de 30 anos de idade e nível superior, em cada nível de renda analisado, tem menor probabilidade de receber renda superior com relação à mulher branca e aos homens em geral. Na Bahia, o quadro é ligeiramente mais desfavorável às mulheres negras do que em São Paulo.

Entre os dois extremos, homem branco e mulher negra, encontram-se os homens negros e as mulheres brancas. Vimos na análise por renda média e mediana, efetuadas na seção 2, que entre os Dirigentes e gerentes os homens negros tinham ligeira superioridade salarial com relação às mulheres brancas. Agora, nesta análise mais detalhada, encontramos resultados que ampliam o conhecimento sobre essa questão. No Estado de São Paulo, ora o homem pardo e negro tem probabilidade maior que a mulher branca de receber renda maior, ora menor, dependendo do nível de renda considerado. Mas, de modo geral, e para os dois ensaios realizados, o homem pardo e negro ante a mulher branca mostra probabilidades inferiores nas faixas de renda intermediárias, e superiores nos níveis mais elevados de rendimento. A discriminação por gênero é maior entre os Dirigentes e gerentes, na medida em que na comparação de ocupados de mesma idade e nível educacional idêntico, as mulheres - pardas e negras, e brancas auferem rendimentos menores que os homens. Porém, faz-se necessário apontar que, nesse grupo ocupacional, o homem pardo e negro está sistematicamente pior que o 
homem branco, e a mulher parda e negra sistematicamente pior que a mulher branca, sempre em termos de probabilidades.

No Estado da Bahia, a discriminação racial é maior entre os homens. Para ocupados de nível escolar médio, os homens brancos apresentam probabilidades sempre acima dos pardos e negros, apesar da diferença decrescer pouco a pouco conforme aumenta o nível de renda. Quando, porém, observamos o comportamento das probabilidades para os ocupados de nível superior, o homem pardo e negro está sempre em uma situação superior à da mulher branca, com diferenças maiores nas faixas intermediárias de renda. Ou a discriminação contra a mulher é maior nos cargos que pagam maiores salários, ou o efeito da educação traz maiores retornos ao homem do que à mulher. $\mathrm{Na}$ realidade, podemos entender que os efeitos não são excludentes e se sobrepóem.

Na Bahia a discriminação sofrida pela mulher negra é alarmante. Para a de nível superior, quanto maior a renda, maior é a diferença nas probabilidades em relação à mulher branca e aos homens. A comparação com os homens brancos agrava ainda mais este quadro: as diferenças nas probabilidades chegam a 40 pontos porcentuais para mulheres negras de 30 anos. Para aquelas com ensino médio completo, as probabilidades são baixas, em torno de $50 \%$, já nas primeiras faixas de renda. A diferença para os demais grupos é relativamente constante conforme aumentam os rendimentos, porém ainda elevada: em torno de 10 pontos porcentuais para os homens negros, 20 para as mulheres brancas, e 30 para os homens brancos.

As evidências apresentadas nesta seção se alinham aos argumentos de que na raiz das diferenças salariais encontram-se os motivos de discriminação devido à raça, pois entre Dirigentes e gerentes, tanto no Estado da Bahia quanto no Estado de Sáo Paulo, as probabilidades dos homens e mulheres pardos e negros, independentemente do nível de escolaridade, são inferiores àquelas dos brancos - homens e mulheres, respectivamente, não justificando as interpretações de que negros e pardos são discriminados pelo fato de serem pobres ou pelo seu status social.

\section{Empregados com Registro}

A análise desta categoria, apresentada na seção 2 , mostra que os diferenciais de rendimento dos homens pardos e negros e mulheres diminuem com relação ao homem branco, e que os rendimentos das mulheres brancas superam aqueles dos homens negros. Realizamos novamente dois ensaios para averiguar com maior acuidade essa questão: Ocupados de 18 anos de idade e ensino médio completo; e Ocupados de 35 anos de idade e antigo primário completo (ou 4 anos de estudo ou $4^{\mathrm{a}}$ série). $\mathrm{O}$ objetivo do primeiro recorte é verificar a discriminação no mercado para jovens recém- 
formados no ensino médio. Sabe-se que o desemprego para a juventude é elevado. Porém, alcançado o tão sonhado primeiro emprego com carteira assinada, quais seriam as probabilidades de rendimentos para esses jovens, todos da mesma idade e com a mesma instrução?

A partir dos Gráficos 5 e 6 podemos extrair três comportamentos. O primeiro refere-se a uma queda acentuada a partir das primeiras faixas de salário, indicando, conforme esperado, a pequena probabilidade dos ocupados jovens auferirem salários elevados devido à sua pouca experiência no mercado de trabalho. O segundo relaciona-se com a diferença salarial inicial entre gênero e raças, que só começa a diminuir na casa dos RS 700,00 , e mesmo assim apenas para os jovens negros e as jovens brancas. O terceiro diz respeito à improbabilidade de qualquer um dos grupos de jovens em análise auferir maiores níveis de salários, indicando a valorização da experiência no mercado de trabalho, independentemente do gênero ou raça.

Novamente, os ocupados brancos do sexo masculino e as ocupadas pardas e negras encontram-se nos extremos, observando-se que o formato da curva dos primeiros decresce de uma maneira mais suave que aquela das últimas. É difícil encontrar uma explicação para tais diferenças salariais em um conjunto de jovens com características tão homogêneas inseridos no mercado de trabalho formal. Uma possível explicação refere-se às variáveis que não são contempladas pelo modelo, como, por exemplo, o tipo de ocupação exercida por esses jovens, que difere dentro da categoria analisada. Uma outra razão pode reportar-se ao maior capital social dos jovens brancos do sexo masculino, que lhe abre as portas para melhores oportunidades. Esta hipótese é plausível, na medida em que, por estarem no início de suas vidas de trabalho, as diferenças entre os novatos, as características não observáveis, não estão ainda em plena evidência. Por fim, parte da diferença também pode ser atribuída ao preconceito contra jovens pardos e negros, e à discriminação de gênero.

Os Gráficos 7 e 8 mostram os resultados para os ocupados de 35 anos que contam apenas com o antigo primário completo, em São Paulo e na Bahia, respectivamente. Em ambos os estados, os homens apresentam probabilidades maiores que as mulheres, e sempre para cada nível salarial a probabilidade dos brancos é maior. Destacam-se ainda dois comportamentos: para qualquer probabilidade, o salário é inferior no Estado da Bahia que em São Paulo, evidenciando as diferenças econômicas regionais; e as diferenças nas probabilidades dos homens pardos e negros e das mulheres brancas caem mais rapidamente entre os baianos, praticamente se igualando na faixa dos R $\$ 500,00$, fato que só acontece por volta dos R \$ 900,00 entre os paulistas. 


\section{Empregados sem Registro}

A estimação do modelo para esta categoria apresentou resultados mais frágeis relativamente àqueles das duas categorias anteriores, em termos de significância para a variável raça. ${ }^{6}$ Isto reflete uma tendência à eliminação da discriminação entre esses trabalhadores e até mesmo sua ausência em alguns casos. No entanto, realizamos os ensaios na medida em que os resultados apontam indícios de discriminação por gênero. Foram escolhidos os seguintes grupos: Ocupados de 20 anos e Ensino fundamental completo; e Ocupados de 40 anos e Antigo primário completo (4 anos de estudo).

No Gráfico 9, observam-se, logo de início, as baixas probabilidades, desde os primeiros níveis de rendimento, para todos os ocupados de 20 anos de idade e ensino fundamental completo no Estado da Bahia. Esses empregados sem registro possuem baixa probabilidade de obter até mesmo R\$200,00 de renda. Mesmo o homem branco, que sempre está em melhor situação perante os demais, possui apenas $40 \%$ de probabilidade de receber mais de R $\$ 200,00$ por mês, e menos de $5 \%$ de perceber rendimentos na faixa dos R $\$ 600,00$. Isso reflete o baixo rendimento próprio desta forma de inserção, implicando menores diferenças nas probabilidades entre os quatro grupos por gênero $\mathrm{e}$ raça que estamos analisando. A mesma situação ocorre para as pessoas de 40 anos que possuem apenas 4 anos de estudo (Gráfico 10). As probabilidades são baixas e próximas umas das outras. Comparando esses dois gráficos, percebe-se que nessa situação de emprego a experiência no mercado de trabalho não conta muito em termos de remuneração, pois para os primeiros níveis de renda, provavelmente onde se encontra a maioria desses ocupados, as probabilidades dos mais jovens são maiores que as dos mais velhos, indicando que essas pequenas diferenças ocorrem devido à escolaridade. No entanto, um detalhe deve ser mencionado, ainda sobre os primeiros estratos de renda: os ocupados brancos apresentam probabilidades ligeiramente maiores que as dos pardos e negros, evidenciando que a despeito da categoria Empregados sem registro apreender um grupo menos desigual de ocupados em termos de renda média, ainda há espaço para a discriminação racial.

Em São Paulo, ao contrário da Bahia, a discriminação volta-se contra a mulher (Gráficos 11 e 12). Para os mesmos grupos até aqui analisados, no estado do Nordeste, na categoria dos empregados sem registro - ocupados de 20 anos com ensino fundamental completo e ocupados de 40 anos com antigo primário completo -, os homens apresentam maiores probabilidades em relação às mulheres, indistintamente da raça. Outra diferença entre os dois estados é que em São Paulo os ocupados de 40 anos apresentam maiores probabilidades do que os ocupados na faixa etária de 20 anos, indicando que no estado do Sudeste a tendência é a valorização da experiência, enquanto na Bahia é a

6 Em São Paulo, até R \$ 1.000,00, não apresentaram significância as faixas de R \$100,00, R \$ 200,00, R \$ 400,00 e R\$500,00. Na Bahia, as faixas de R\$ 100,00, R\$400,00, R\$700,00 e R\$ 800,00. 
maior escolaridade. Por fim, há uma semelhança entre os dois estados: as probabilidades são baixas para todos os ocupados analisados, evidenciando as dificuldades de obtenção de renda por parte dos trabalhadores sem registro. ${ }^{7}$

\section{Primeiro Quintil de Renda Familiar Per Capita}

As pessoas que compõem este grupo são as mais pobres dos estados selecionados. Sabemos que a renda média dessas pessoas é muito baixa, com renda familiar per capita não alcançando RS 70,00 por mês, e que a grande maioria tem escolaridade máxima de até o ensino fundamental incompleto. Nesta situação de extremo desfavorecimento, há espaço para a desigualdade? Os resultados do modelo indicam que neste grupo há discriminação por gênero, ou seja, contra a mulher. Os coeficientes para esta variável são significantes, confirmando o que vimos na análise da renda média: a renda das mulheres, brancas e negras ou pardas é menor que a dos homens. Entretanto, os coeficientes para cor ou raça estimados não apresentam significância. Deste modo, não podemos afirmar que a raça tem influência sobre a probabilidade de obtenção de renda e, portanto, conclui-se que não existe essa discriminação entre os mais pobres.

As estimações realizadas para o Estado de São Paulo não apresentam significância para nenhuma variável, exceto para os coeficientes de gênero (acima de R $\$ 300,00)^{8}$ e de escolaridade. Deste modo, para este grupo, não podemos inferir qualquer desigualdade relevante devido à raça, idade e/ou escolaridade. A significância dos coeficientes para gênero a partir de níveis de renda acima de R $\$ 300,00$ não apresenta muita relevância na prática, uma vez que a maioria dos ocupados deste grupo possui rendimentos bem abaixo desse patamar. Na seção 2 indicamos que o maior nível de remuneração dos pardos e negros poderia estar associado aos valores extremos - outliers - que elevam ou diminuem em excesso a renda média. Os resultados dessas estimações confirmam essa conclusão ao não diferenciar os ocupados negros e pardos dos brancos. Por outro lado, a renda superior dos homens com relação à das mulheres pode ser parcialmente explicada por meio do modelo, que aponta, em alguns casos, renda menor para as mulheres, o suficiente para alterar a renda média.

No caso da Bahia, também ocorre o mesmo: para a variável raça, nenhum coeficiente mostra-se significante, indicando que não há diferenças de tratamento de brancos ou pardos e negros no mercado de trabalho. A diferença entre as rendas médias, portanto, deve se dar por conta do gênero, pois estes coeficientes, sim, têm significância nas ren-

7 Nos Gráficos de 5-12, a queda observada nas distâncias entre as curvas conforme a renda aumenta reflete, provavelmente, mais a dificuldade de obtenção daquela renda em virtude dos baixos salários praticados no mercado de trabalho brasileiro do que propriamente o enfraquecimento da discriminação.

8 Para a variável de escolaridade, há significância apenas para a faixa de R \$300,00. 
das menores. Um ponto a ressaltar é que, diversamente do caso paulista, as variáveis de idade e anos de estudo apresentam significância a 1\%. Isto mostra que no Estado da Bahia existe retorno positivo para aqueles mais experientes e educados. Porém, tais retornos não se mostram suficientes para eliminar a discriminação por gênero, na medida em que a mulher apresenta renda média menor que os homens.

\section{CONSIDERAÇÕES FINAIS}

Com o objetivo de verificar o grau de discriminação, estimou-se um modelo de variável dependente binária, que nos permitiu medi-lo em termos de probabilidades. $\mathrm{O}$ modelo probit foi aplicado em três categorias de inserção na ocupação que estruturam o mercado de trabalho - Dirigentes e gerentes, Empregados com registro e Empregados sem registro, e para os ocupados que compóem as famílias do primeiro quintil da distribuição de renda familiar per capita, totalizando 12 ensaios, realizados com microdados da PNAD para o ano de 2002.

Este estudo tanto ratifica resultados que são apresentados pela literatura especializada quanto traz evidências adicionais sobre a discriminação por gênero e raça nos mercados de trabalho formal e informal e entre os grupos sociais mais pobres. Entre os resultados que foram confirmados, enfatizamos o crescimento da discriminação com o aumento da escolaridade e a maior discriminação contra a mulher negra. Por outro lado, há indícios de práticas de discriminação distintas entre os mercados de trabalho formal e informal. No primeiro - Empregados com registro - predomina a discriminação por gênero, enquanto no segundo - Empregados sem registro - destaca-se a discriminação por raça. Entre os mais pobres - primeiro quintil de renda familiar per capita - verifica-se a discriminação por gênero, não se observando a discriminação segundo a raça.

Adicionalmente, apontamos dois resultados que se contrapóem à tese de que no Brasil a discriminação racial se confunde com a discriminação contra os mais pobres. No Estado da Bahia, entre os Dirigentes e gerentes, ocupados de 30 anos e ensino médio completo, e na categoria de Empregados sem registro, ocupados que possuem nível de escolaridade de terceiro grau no Estado de São Paulo, negros e pardos apresentam probabilidades de obtenção de renda menores que os brancos, sejam homens ou mulheres. Ou seja, se a hipótese de que a discriminação existente no mercado de trabalho brasileiro deriva de preconceito contra as pessoas mais pobres, ao invés de ser motivada por raça, no âmbito dessas categorias não deveria ser observado diferenças substanciais nas probabilidades de obtenção de renda, pois os ocupados que compõem essas categorias não se caracterizam como integrantes de uma situação de desvantagem no mercado de trabalho. 
Por fim, temos uma última consideração. A partir do modelo exposto na seção 1, vimos que mercados distintos - pequena oferta/oferta abundante de trabalhadores apresentam, no plano teórico, resultados diferentes. Onde a oferta é pequena, não teríamos diferenciais de salário e os empregadores que discriminam poderiam maximizar lucros, enquanto onde a oferta é abundante, teríamos ineficiência no mercado, ou seja, não maximização de lucros e diferenciais de salário. Apesar disso, essa conclusão não necessariamente exclui a possibilidade de ocorrência de outros resultados. A análise realizada neste artigo indicou que, embora os mercados de trabalho de São Paulo e Bahia sejam distintos em sua composição racial negra/branca, não presenciamos aquela situação. A principal justificativa remete à definição de oferta - pequena ou abundante. Não se pode afirmar categoricamente que em São Paulo temos o primeiro caso e na Bahia o segundo. Outro ponto diz respeito à proporção entre empregadores que discriminam e os que não discriminam. A maior presença de empregadores discriminadores tende a dificultar a absorção da oferta de trabalhadores sujeitos ao preconceito, de modo que, dependendo da combinação entre aquela proporção e a composição da oferta, podemos ter, teoricamente, o mesmo resultado encontrado neste estudo. Assim, mesmo na presença de mercados distintos, os resultados semelhantes se justificam pelo motivo que estamos enfatizando: a discriminação está, em maior ou menor grau, presente no mercado de trabalho brasileiro.

\section{BIBLIOGRAFIA}

Arrow, K. J. Discrimination in the labour market: some models of racial discrimination in the labour market, In: King, J. E., Readings in labour economics: edited readings with commentaries. New York: Oxford University Press, 1980.

Borjas, G. J. Labor economics. McGraw-Hill, 1996.

Castro, C. M. O preço da cor: os diferenciais raciais na distribuição de renda no Brasil: comentário. Pesquisa e Planejamento Econômico, Rio de Janeiro, v. 10, n. $3,1980$.

DIEESE. 20 de novembro: dia nacional da consciência negra. Boletim DIEESE: Edição Especial, novembro de 2001.

. Mulher negra: dupla discriminação nos mercados de trabalho metropolitanos. Boletim DIEESE: Edição Especial, novembro de 2003.

Ehrenberg, R. G.; Smith, R. S. Modern labor economics: theory and public policy. Estados Unidos: Addison-Wesley Educational Publishers Inc., 1997.

Fernandes, F. A integração do negro à sociedade de classes. São Paulo: Dominus Editora, 1964. 
Ferreira, F. H. G. Os determinantes da desigualdade de renda no Brasil: luta de classes ou heterogeneidade educacional? In: Henriques, R. (org.), Desigualdade e pobreza no Brasil. Rio de Janeiro: IPEA, 2000.

Griffiths, W. E.; Hill, R. C.; Judge, G. C. Learning and practicing econometrics. Estados Unidos: John Wiley \& Sons, Inc., 1993.

Lovell, P. A. Raça, classe, gênero e discriminação salarial no Brasil. Estudos Afroasiáticos, Rio de Janeiro, n. 22, p. 85-98, setembro de 1992.

Ramos, L.; Vieira, M. L. Determinantes da desigualdade de rendimento no Brasil nos anos 90: discriminação, segmentação e heterogeneidade dos trabalhadores. In: Henriques, R. (org.), Desigualdade e pobreza no Brasil. Rio de Janeiro: IPEA, 2000.

Silva, N. V. O preço da cor: os diferenciais raciais na distribuição de renda no Brasil. Pesquisa e Planejamento Econômico, Rio de Janeiro, v. 10, números l e 3, 1980.

Soares, S. S. D. O perfil da discriminação no mercado de trabalho - homens negros, mulheres brancas e mulheres negras. Texto para discussão, $\mathrm{N}^{\circ} 769$, Brasília: IPEA, novembro 2000.

Wood, C. H.; Carvalho, J. A. M. de. A demografia da desigualdade no Brasil. Rio de Janeiro: IPEA, 1994. 
ANEXO 1 - GRÁFICOS REFERENTES AOS 12 ENSAIOS REALIZADOS

GRÁFICO I-OCUPADOS DE 30 ANOS E NÍVEL SUPERIOR - SÃO PAULO

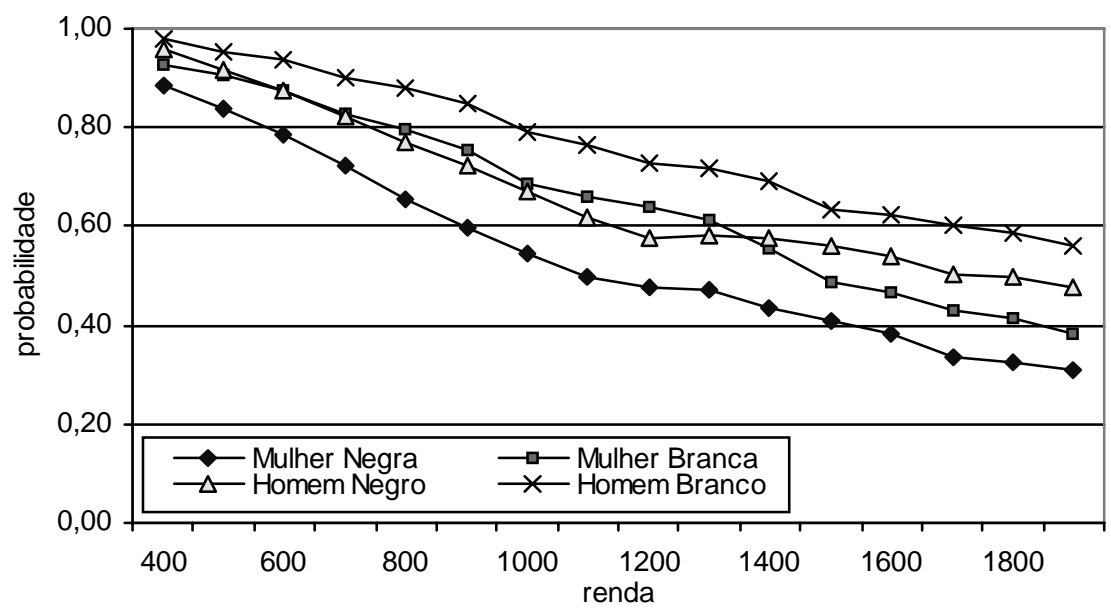

GRÁFICO 2 - OCUPADOS DE 30 ANOS E ENSINO MÉDIO COMPLETO - SÃO PAULO

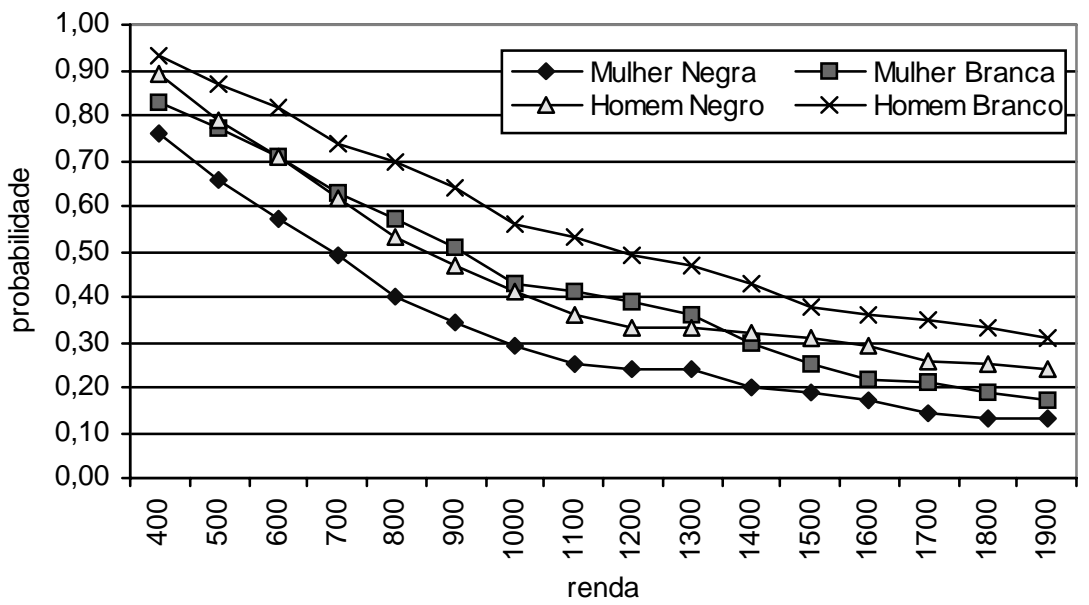




\section{GRÁFICO 3 - OCUPADOS DE 30 ANOS E NÍVEL SUPERIOR - BAHIA}

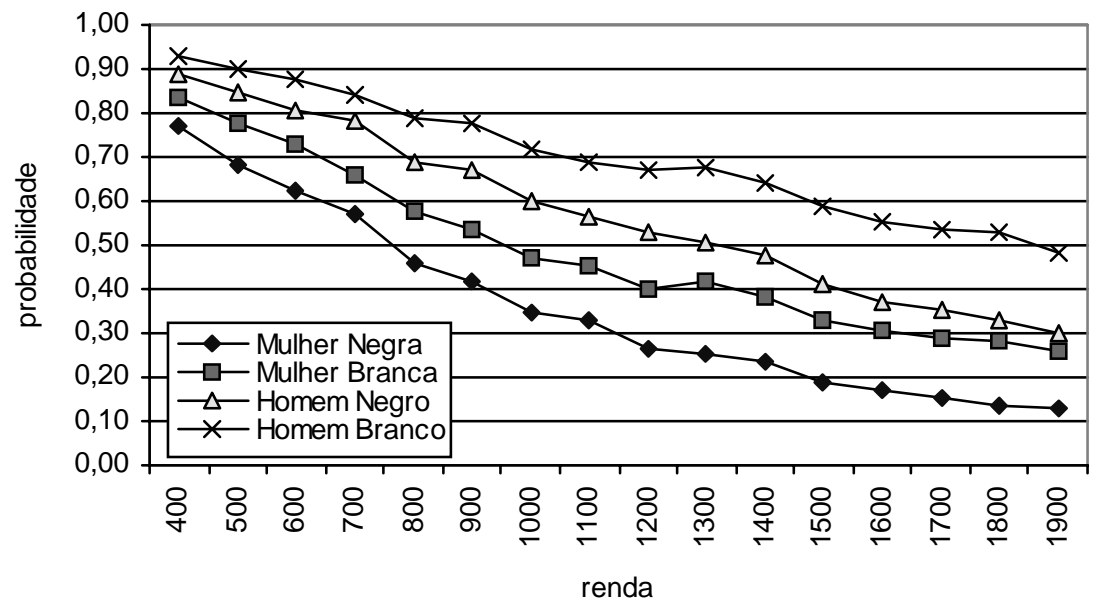

\section{GRÁFICO 4 - OCUPADOS DE 30 ANOS E ENSINO MÉDIO COMPLETO - BAHIA}

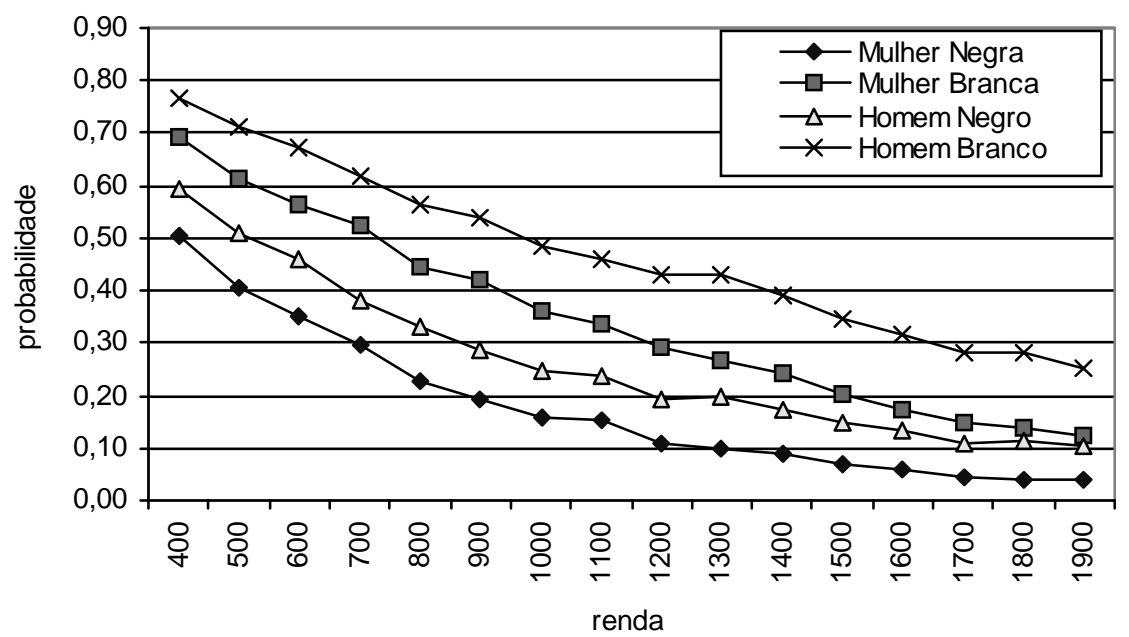


GRÁFICO 5 - OCUPADOS DE 18 ANOS E ENSINO MÉDIO COMPLETO - SÃO PAULO

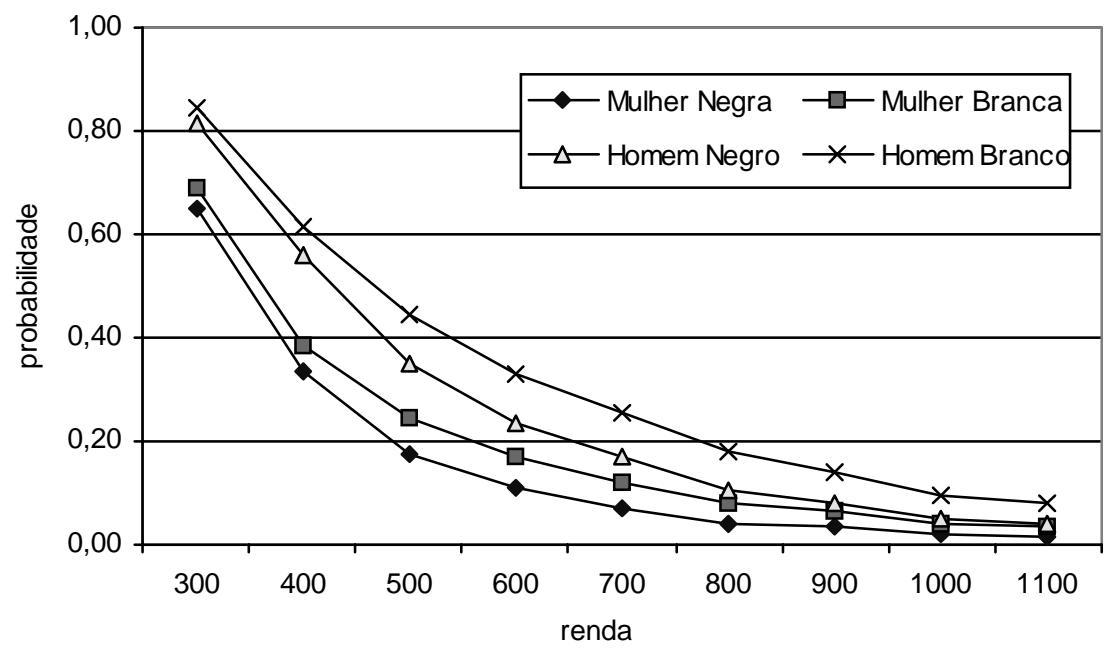

GRÁFICO 6 - OCUPADOS DE 18 ANOS E ENSINO MÉDIO COMPLETO BAHIA

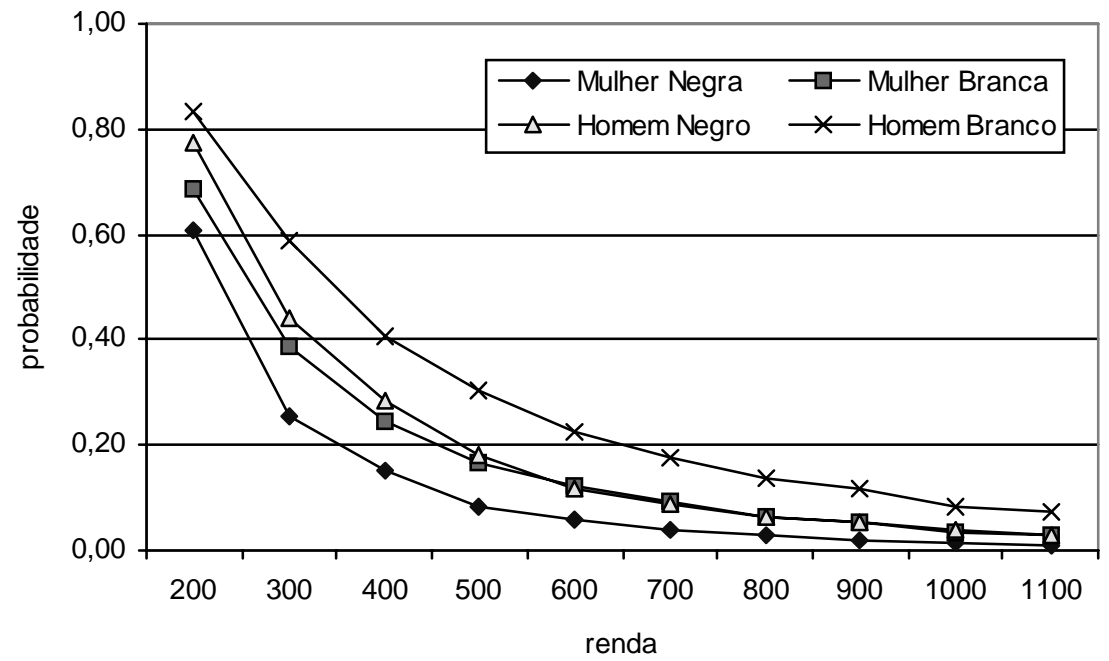




\section{GRÁFICO 7 - OCUPADOS DE 35 ANOS E ANTIGO PRIMÁRIO COMPLETO - SÃO PAULO}

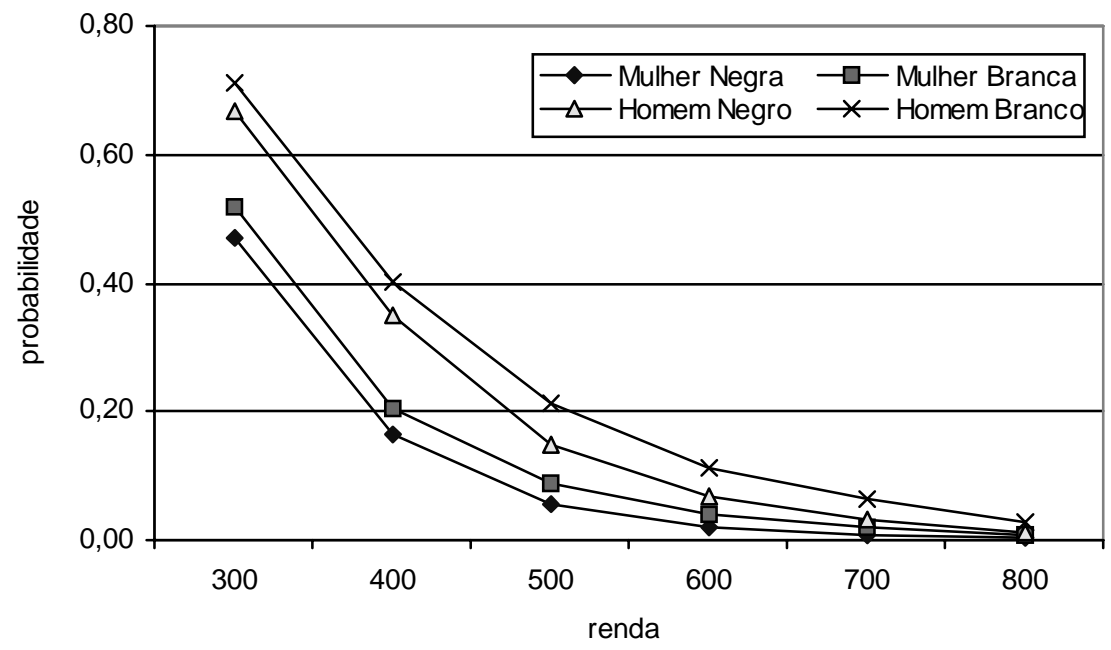

\section{GRÁFICO 8 - OCUPADOS DE 35 ANOS E ANTIGO PRIMÁRIO COMPLETO -} BAHIA

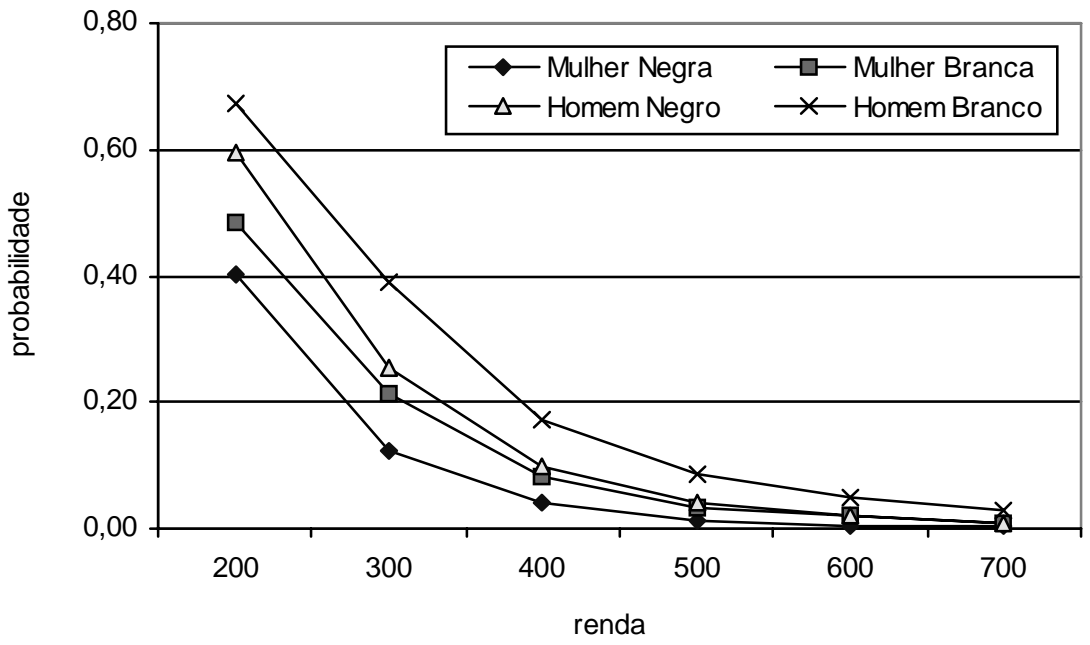


GRÁFICO 9 - OCUPADOS DE 20 ANOS E ENSINO FUNDAMENTAL COMPLETO - BAHIA

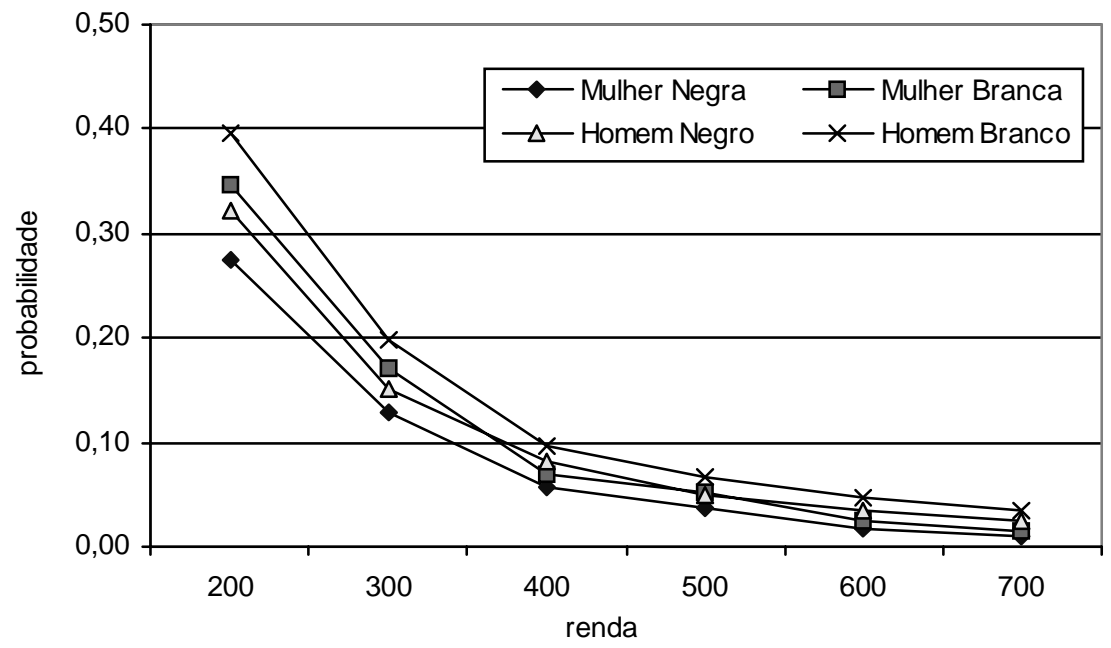

GRÁFICO 10 - OCUPADOS DE 40 ANOS E ANTIGO PRIMÁRIO COMPLETO - BAHIA

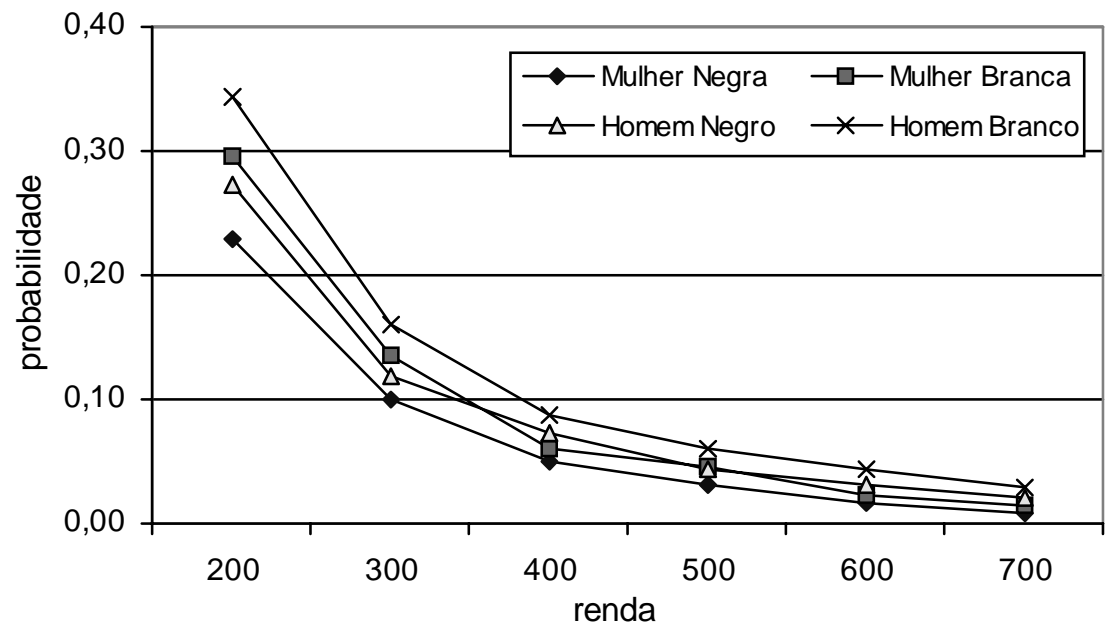


GRÁFICO 11 - OCUPADOS DE 20 ANOS E ENSINO FUNDAMENTAL COMPLETO - SÃO PAULO

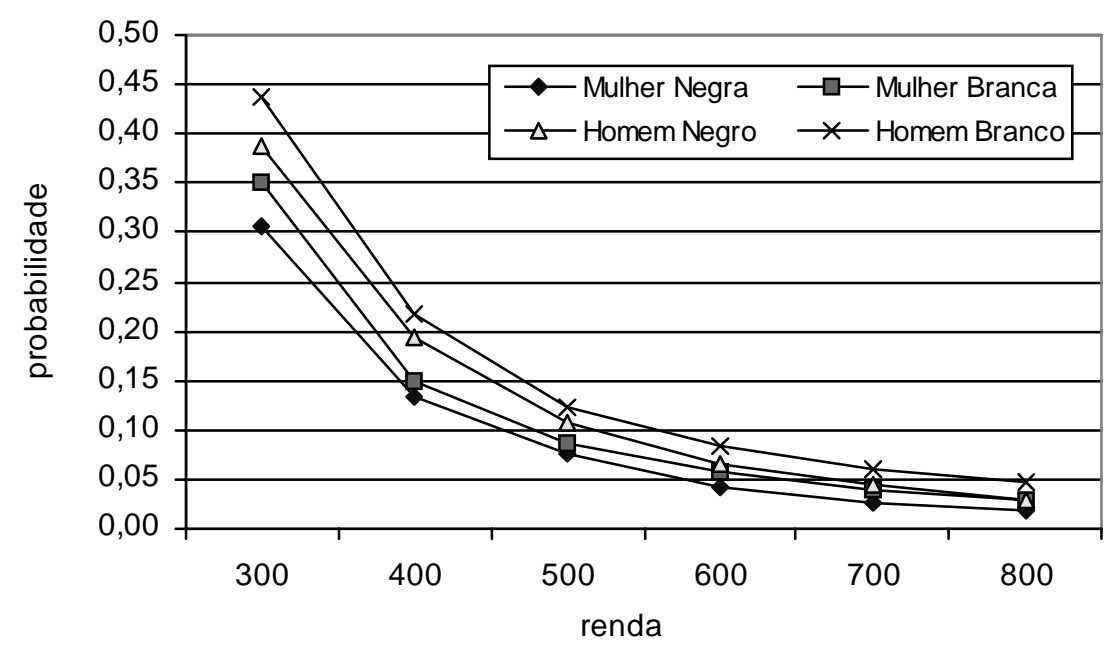

GRÁFICO 12 - OCUPADOS DE 40 ANOS E ANTIGO PRIMÁRIO COMPLETO SÃO PAULO

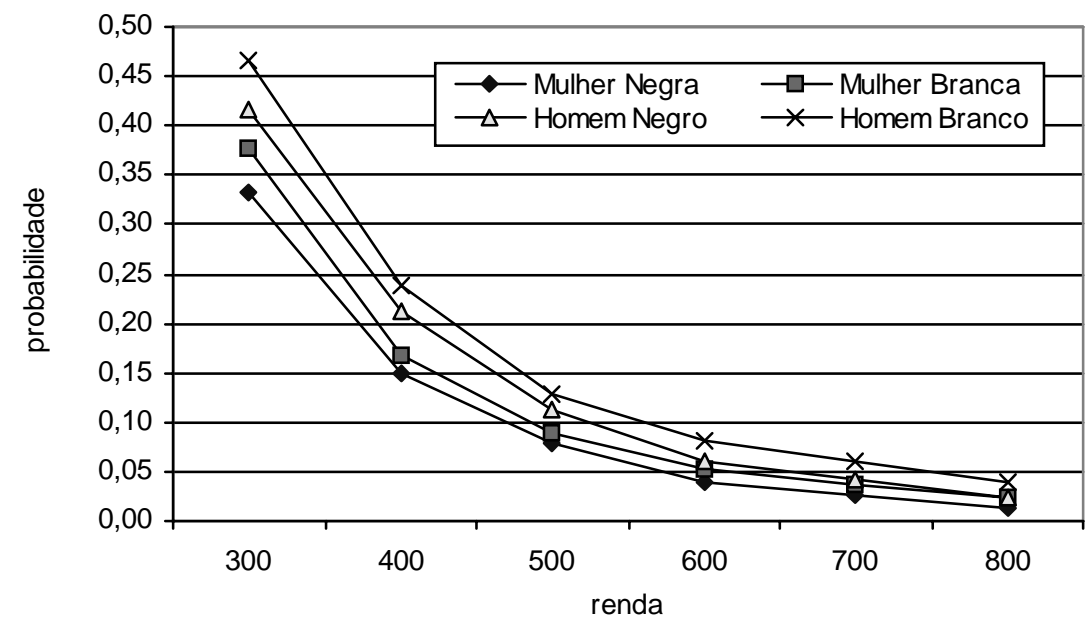




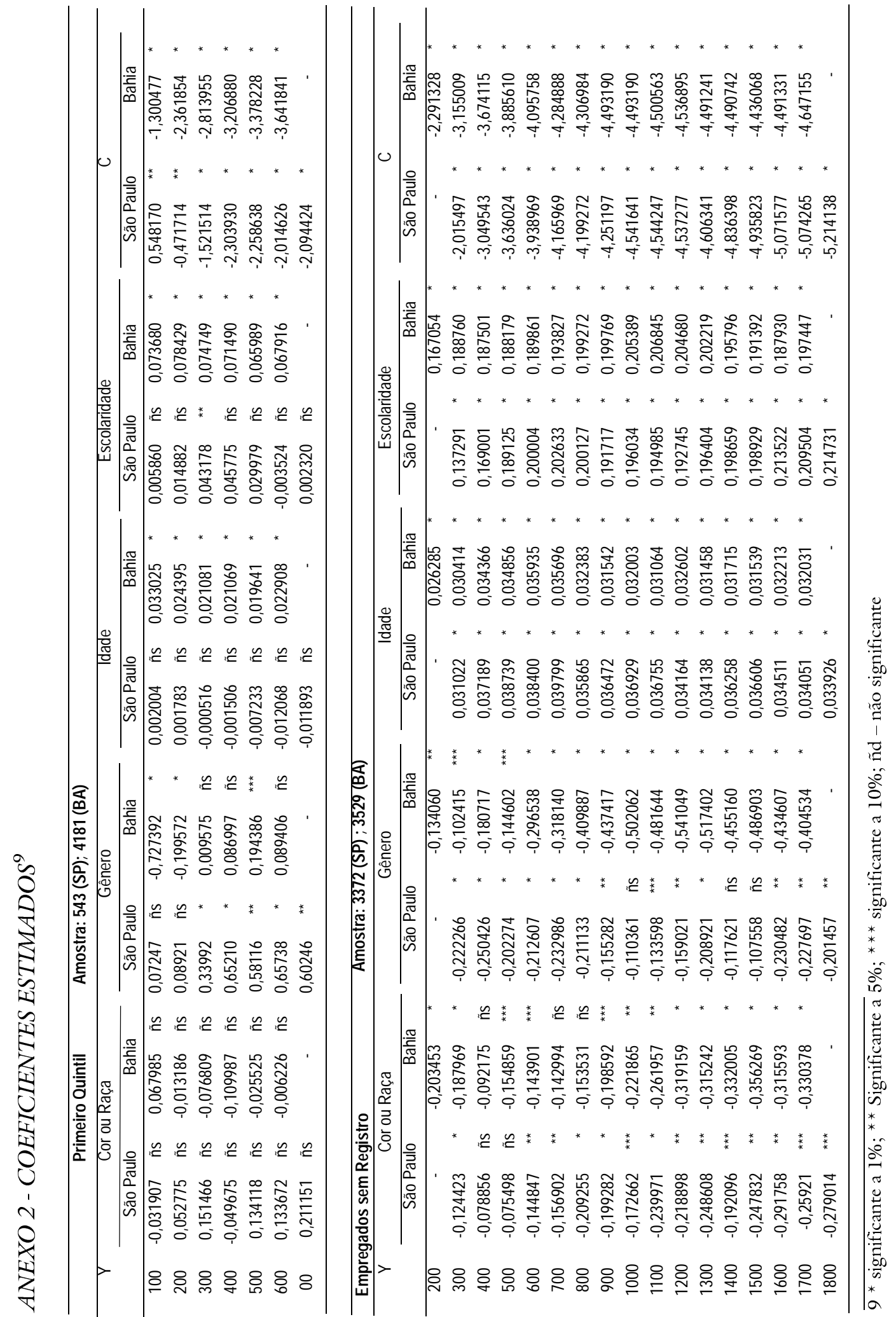

Est. econ., São Paulo, 35(4): 767-795, out-dez 2005 


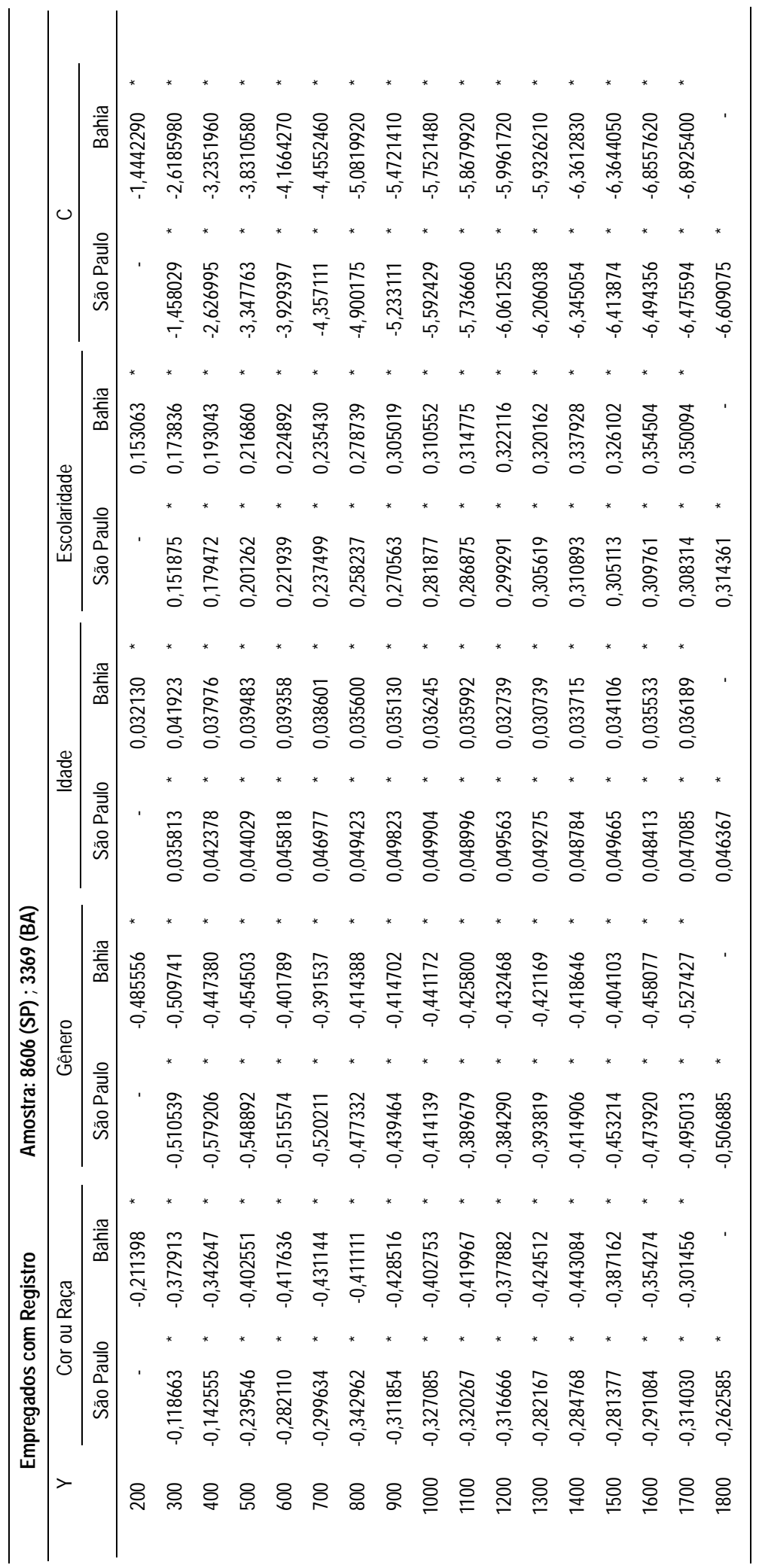

Est. econ., São Paulo, 35(4): 767-795, out-dez 2005 


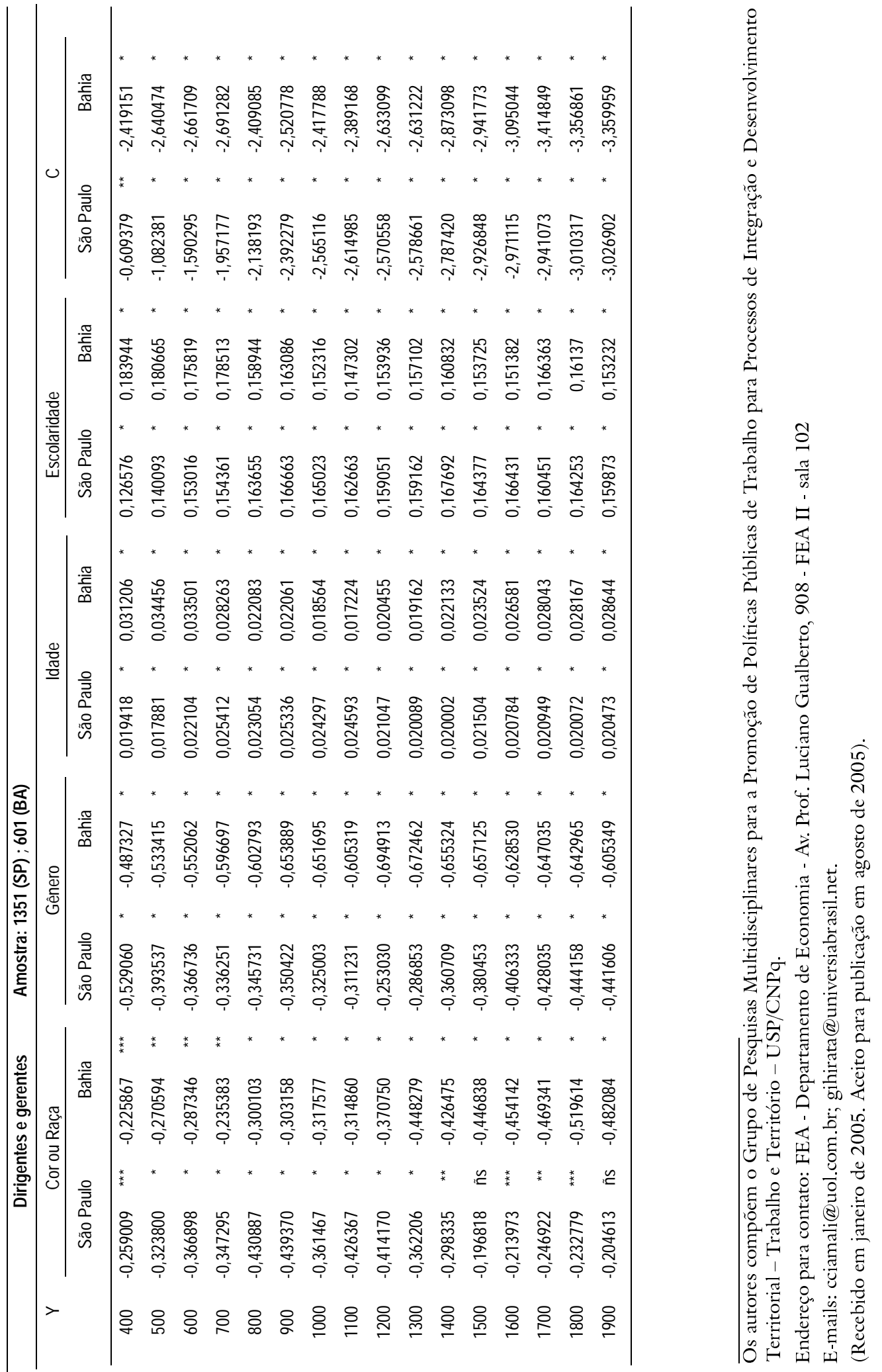

Est. econ., São Paulo, 35(4): 767-795, out-dez 2005 